\title{
Natural history of the spontaneous reperfusion of human cerebral infarcts as assessed by ${ }^{99 \mathrm{~m}} \mathrm{Tc}$ HMPAO SPECT
}

\author{
J V Bowler, J P H Wade, B E Jones, K S Nijran, T J Steiner
}

\begin{abstract}
Objective-Little is known about the effect of spontaneous reperfusion of human cerebral infarcts. Single photon emission computerised tomography (SPECT) data were analysed from a study using ${ }^{99} \mathrm{Tc}^{\mathrm{m}}$ HMPAO $\left({ }^{99} \mathrm{Tc}^{\mathrm{m}}\right.$ hexamethylpropyleneamine oxime) in human cerebral infarction for the frequency of reperfusion and to see if it affected infarct size, oedema, haemorrhagic transformation, or functional outcome.
\end{abstract}

Methods-Fifty sequential cases of ischaemic stroke were studied with $124{ }^{99} \mathrm{Tc}^{\mathrm{m}}$ HMPAO SPECT at around one day, one week, and three months after stroke along with detailed clinical and functional assessments.

Results-Visually apparent reperfusion occurred in 14 of 50 patients $(28 \%)$ with a mean delay of 5.8 days and reperfusion was seen in seven others in whom it was identified on the basis of changes in perfusion deficit volume. It occurred in 13 of 23 embolic events but only in three of 23 other events. In only two cases did spontaneous reperfusion occur early enough to preserve tissue or function. Reperfusion did not otherwise reduce infarct size, or improve clinical or functional outcome, and was not associated with oedema but an association with haemorrhagic transformation was suggested. Reperfusion significantly decreased the apparent perfusion defect as measured by SPECT one week from the ictus, but was mostly non-nutritional and transient. The mean volume of tissue preserved by nutritional reperfusion was $10 \mathrm{~cm}^{3}$, but this was unequally distributed between cases. Late washout of ${ }^{99} \mathrm{Tc}^{\mathrm{m}}$ HMPAO from areas of hyperaemic reperfusion may be a good prognostic marker but is a rare phenomenon and too insensitive to be of general applicability.

Conclusions-Spontaneous reperfusion after cerebral infarction occurs in $42 \%$ of cases within the first week but is associated with clinical improvement in only $2 \%$. It has few adverse consequences although it may be associated with haemorrhagic transformation.

(F Neurol Neurosurg Psychiatry 1998;64:90-97)

Keywords: SPECT; reperfusion; cerebral infarction; natural history
Impairment of cerebral blood flow is the underlying abnormality in cerebral infarction and its restoration is crucial in preserving neural tissue. This is the basis of thrombolytic therapy but recent data have shown that non-nutritional reperfusion after streptokinase is harmful. ${ }^{1}$ However, little is known about the natural history of spontaneous reperfusion. Luxury reperfusion was first recognised in $1966 .^{2}$ Several studies ${ }^{3-10}$ have described reperfusion but either have not considered its clinical consequences or the clinical details have been scant. Its frequency and timing in unselected stroke cases are not well documented. The natural history of reperfusion may suggest a maximum time from onset at which reperfusion can be nutritional ${ }^{1}$ and result in clinical improvement or tissue preservation. It will also indicate the degree to which reperfusion is determined by aetiology (thrombotic $v$ embolic infarction), or associated with oedema or haemorrhagic transformation.

${ }^{99} \mathrm{Tc}^{\mathrm{m}}$ hexamethylpropyleneamine oxime $\left({ }^{99} \mathrm{Tc}^{\mathrm{m}}\right.$ HMPAO, Exametazine, Ceretec, Amersham International) is a validated proportional indicator of cerebral blood flow. ${ }^{11-15}$ As part of a prospective study investigating the patterns of change in cerebral blood flow and their clinical correlates in acute stroke, we performed 124 high resolution SPECT scans using ${ }^{99} \mathrm{Tc}^{\mathrm{m}}$ HMPAO. The subjects were 50 consecutive, unselected patients with ischaemic stroke admitted to a district general hospital. As serial assessments of clinical status, perfusion defect and infarct volume determined by both SPECT and CT were available, we analysed the data to determine the natural history and consequences of spontaneous reperfusion in human cerebral infarction.

Various indices measurable from ${ }^{99} \mathrm{Tc}^{\mathrm{m}}$ HMPAO SPECT have been proposed as prognostic indicators but the most recent work has suggested that these add little or nothing to the prognosis determined by simple clinical examination. ${ }^{16-18}$ The redistribution of ${ }^{99} \mathrm{Tc}^{\mathrm{m}}$ HMPAO after hyperaemic reperfusion has been proposed as a prognostic marker ${ }^{19}$ and we performed early and late scans after HMPAO injection on five occasions to further evaluate this.

\section{Patients and methods}

The study was prospective and carried out on sequential patients with first stroke admitted to a general teaching hospital. We have previously reported the methods. ${ }^{16}{ }^{20}$ Briefly, a full neurological examination and SPECT, using 


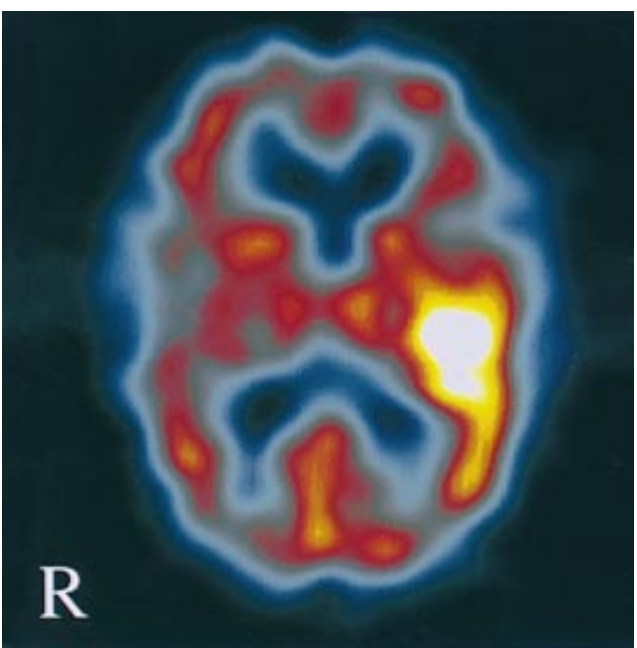

Figure 1 Absolute hyperaemia 1.1 days after a middle cerebral artery embolism.

${ }^{99} \mathrm{Tc}^{\mathrm{m}} \mathrm{HMPAO}$ and the NOVO 810 scanner, which is a dedicated multidetector tomographic head scanner with a resolution of $9 \mathrm{~mm}$ full width at half maximum in the plane of the scan, were carried out as soon as possible after the infarct. The clinical assessment included the Canadian neurological scale ${ }^{21}$ and, for functional evaluation, the Barthel index..$^{22}$ Subsequent assessments were around one week and three months after stroke. Brain CT was carried out usually between three and seven days. Echocardiography, carotid duplex Doppler studies, and ECG were also carried out.

Scans were inspected with full knowledge of the $x$ ray CT result and clinical picture. Reperfusion was identified from SPECT by visual inspection in the first instance.

Reperfusion was defined as either:

(1) an absolute increase in ${ }^{99} \mathrm{Tc}^{\mathrm{m}} \mathrm{HMPAO}$ uptake in the affected volume defined by the CT, MRI, or later SPECT. This type of reperfusion, which we have termed absolute hyperaemia, could therefore be identified on any scan without the need for an earlier scan showing decreased ${ }^{99} \mathrm{Tc}^{\mathrm{m}} \mathrm{HMPAO}$ uptake (fig 1).
(2) Relative increase in ${ }^{99} \mathrm{Tc}^{\mathrm{m}}$ HMPAO uptake in the affected volume ("relative reperfusion"), in one or more ${ }^{99} \mathrm{Tc}^{\mathrm{m}}$ HMPAO SPECT, compared with the same volume in an earlier SPECT (fig 2).

Absolute hyperamia was readily identified; in addition the serial SPECT for all the patients without absolute hyperamia were scrutinised for relative reperfusion. Absolute hyperamia was confirmed and quantified using circular regions of interest twice the resolution of the scanner $(18 \mathrm{~mm})$ in diameter. These were placed manually over the whole of the affected region and the equivalent contralateral region. The mean counts from the region of interest on each side were averaged and the ratio abnormal:normal calculated. If reperfusion occupied only part of the volume of the infarct, the reperfused portion of the volume was tested separately. The criterion confirming relative reperfusion and hyperaemia was that the change between the reperfused and nonreperfused scans was $>2$ SD outside the reference range for right to left difference. ${ }^{23}$ In addition, we noted any case in which the apparent perfusion defect was lower in the second SPECT than either the first or third SPECT; we interpreted this as suggesting lesser degrees of reperfusion, detectable only by volume measurements.

The measurement of perfusion defects has been described previously. ${ }^{16}$ The brain CT was examined for oedema and haemorrhagic infarction. Oedema was deemed to be present if there was effacement of the sulci overlying the infarct or compression or displacement of adjacent structures on the CT.

The aetiology was based on the history, ECG, echocardiogram, and duplex Doppler as embolic (cardiac or artery to artery) or thrombotic (occlusion in situ). SPECT results were not used to classify the aetiology. Lacunes were not considered to have a unique pathogenesis and infarcts consistent with low flow (watershed infarcts) were classified according to the primary aetiology. Embolic infarcts had to be of sudden onset when the mode of onset was

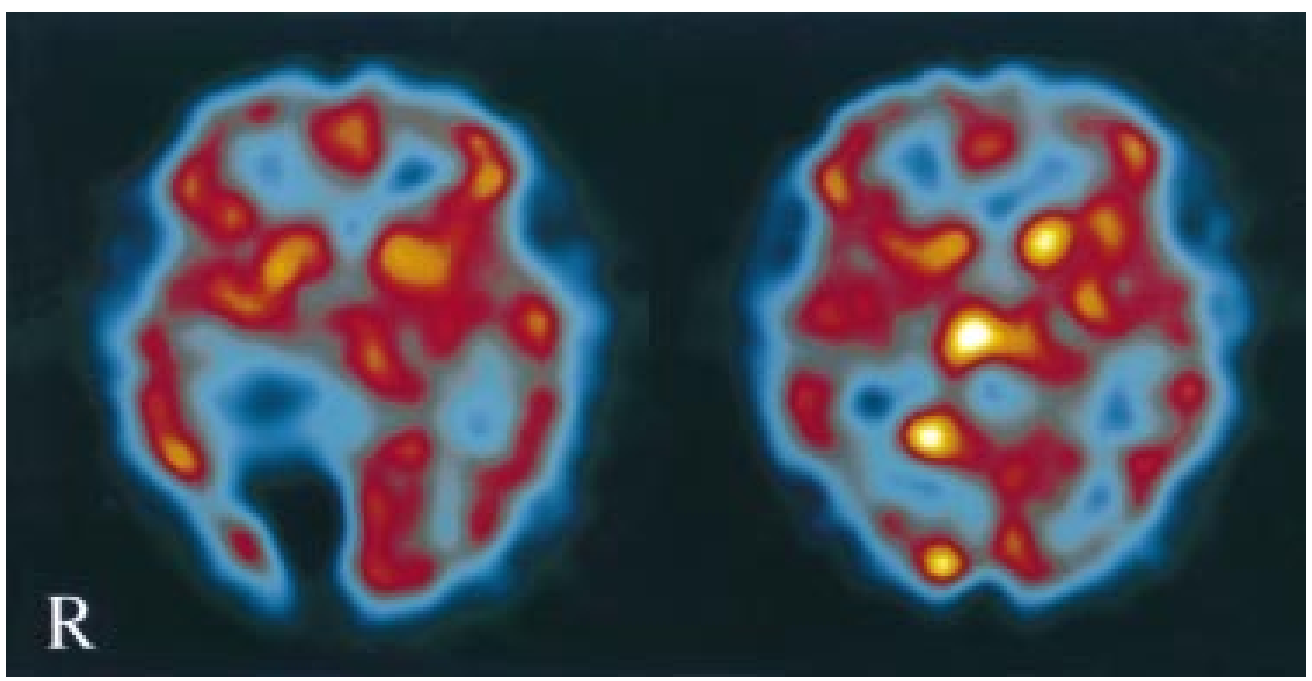

Figure 2 Relative reperfusion: a right posterior cerebral artery infarct scanned 1.7 days after onset (left) shows a large perfusion deficit with almost complete resolution of the perfusion defect on the second scan (right) at 8.7 days. 
Table 1 CT and SPECT scanning times and perfusion defects $\left(\mathrm{cm}^{3}\right) . H=$ hyperaemic, $R=$ relative, $V=$ detected on volume measurements only, $X=$ no evidence for reperfusion

\begin{tabular}{|c|c|c|c|c|c|c|c|c|c|c|c|}
\hline \multirow[b]{3}{*}{ Case No } & \multirow[b]{3}{*}{$\operatorname{Sex}$} & \multirow[b]{3}{*}{ Age } & \multirow[b]{3}{*}{ Reperfusion type } & \multicolumn{4}{|c|}{ SPECT and CT timing (days) } & \multicolumn{4}{|c|}{$\begin{array}{l}\text { Perfusion defects and infarct volumes } \\
\left(\mathrm{cm}^{3}\right)\end{array}$} \\
\hline & & & & \multicolumn{3}{|c|}{ SPECT } & \multirow[b]{2}{*}{$C T$} & \multicolumn{3}{|c|}{ SPECT } & \multirow[b]{2}{*}{$C T$} \\
\hline & & & & $1 s t$ & $2 n d$ & $3 r d$ & & $1 s t$ & $2 n d$ & $3 r d$ & \\
\hline 2 & $\mathrm{~F}$ & 77 & $\mathrm{H}$ & 0.8 & 6.8 & 106 & 1 & 75 & 70 & 73 & 72 \\
\hline 3 & M & 54 & $\mathrm{~V}$ & 0.8 & 7.6 & 105 & 2.6 & 164 & 85 & 176 & 90 \\
\hline 4 & $\mathrm{M}$ & 74 & $\mathrm{X}$ & 0.6 & - & - & 4.6 & 23 & - & - & 16 \\
\hline 5 & $\mathrm{~F}$ & 66 & $\mathrm{H}$ & 0.5 & 13 & 99 & 0.7 & 52 & 0 & 56 & 38 \\
\hline 7 & $\mathrm{~F}$ & 76 & $\mathrm{R}$ & 1 & 6 & 93 & 0.3 & 4 & 0 & 6 & 0 \\
\hline 9 & $\mathrm{~F}$ & 76 & $\mathrm{X}$ & 1 & 7.2 & 91 & 4.3 & 0 & 0 & 0 & 0 \\
\hline 10 & M & 63 & $\mathrm{~V}$ & 0.8 & 3.8 & 101 & 2.8 & 2 & 1 & 15 & 7 \\
\hline 11 & M & 72 & $\mathrm{H}$ & 1.1 & 6.1 & 66 & 6 & 121 & 46 & 116 & 90 \\
\hline 12 & $\mathrm{~F}$ & 41 & $\mathrm{X}$ & 4.2 & - & 136 & 0.5 & 1 & - & 1 & 0 \\
\hline 13 & M & 83 & $\mathrm{X}$ & 1.3 & 5.3 & 95 & 5.2 & 0 & 0 & 0 & 0 \\
\hline 14 & M & 57 & $\mathrm{X}$ & 1.2 & 12 & 98 & 6.2 & 0 & 0 & 0 & 1 \\
\hline 15 & M & 63 & $\mathrm{X}$ & 0.7 & - & - & 0.9 & 215 & - & - & 3 \\
\hline 16 & $\mathrm{~F}$ & 81 & $\mathrm{H}$ & 1.2 & 8.3 & - & 2.2 & 49 & 5 & - & 81 \\
\hline 18 & $\mathrm{~F}$ & 66 & $\mathrm{X}$ & 1.9 & 4.9 & 95 & 4.9 & 0 & 14 & 13 & 6 \\
\hline 19 & M & 55 & $\mathrm{X}$ & 12 & - & 181 & 4 & 3 & - & 1 & 3 \\
\hline 20 & $\mathrm{~F}$ & 80 & $\mathrm{R}$ & 1.2 & 7.2 & 84 & 6.1 & 11 & 5 & 19 & 32 \\
\hline 21 & M & 41 & $\mathrm{X}$ & 1.8 & 23 & - & 1.3 & 93 & 59 & - & 0 \\
\hline 22 & M & 62 & $\mathrm{X}$ & 2.1 & 6.2 & 92 & 5.2 & 3 & 7 & 34 & 21 \\
\hline 23 & $\mathrm{~F}$ & 76 & $\mathrm{X}$ & 2 & 6 & - & 4 & 4 & 14 & - & 12 \\
\hline 24 & M & 70 & $\mathrm{X}$ & 1.3 & 7.1 & - & 6.2 & 61 & 106 & - & 30 \\
\hline 25 & M & 56 & $\mathrm{X}$ & 1 & - & - & 0.2 & 197 & - & - & 0 \\
\hline 26 & $M$ & 73 & $\mathrm{~V}$ & 0.5 & 6.5 & 99 & 0.8 & 2 & 1 & 2 & 0 \\
\hline 27 & $\mathrm{~F}$ & 59 & $\mathrm{H}$ & 1.1 & 3.3 & 90 & 1 & 5 & 1 & 6 & 3 \\
\hline 28 & $\mathrm{~F}$ & 77 & $\mathrm{R}$ & 0.8 & 6.8 & 94 & 3.8 & 16 & 3 & 17 & 3 \\
\hline 30 & $\mathrm{~F}$ & 61 & V & 0.7 & 6.7 & 122 & 3.7 & 159 & 102 & 210 & 87 \\
\hline 31 & $\mathrm{~F}$ & 73 & $\mathrm{X}$ & 1.3 & 6.3 & 120 & 2.5 & 134 & 155 & 169 & 154 \\
\hline 32 & $\mathrm{~F}$ & 68 & V & 3.2 & 7.2 & 69 & 7.1 & 9 & 3 & 6 & 3 \\
\hline 33 & M & 65 & $\mathrm{X}$ & 0.8 & - & - & 3.8 & 165 & - & - & 81 \\
\hline 34 & $\mathrm{~F}$ & 71 & $\mathrm{X}$ & 1.1 & - & - & - & 112 & - & - & - \\
\hline 35 & $M$ & 67 & $\mathrm{X}$ & 1 & 4 & - & 3.2 & 0 & 0 & - & 0 \\
\hline 36 & $\mathrm{~F}$ & 67 & $\mathrm{X}$ & 0.8 & 3.8 & 115 & 4 & 0 & 0 & 0 & 2 \\
\hline 37 & $\mathrm{~F}$ & 81 & $\mathrm{X}$ & 0.8 & - & - & 5.8 & 58 & - & - & 225 \\
\hline 38 & M & 43 & $\mathrm{H}$ & 1.7 & 8.5 & - & 1.6 & 168 & 5 & - & 91 \\
\hline 40 & $\mathrm{~F}$ & 81 & $\mathrm{X}$ & 0.3 & 7.2 & 62 & 3.4 & 90 & 91 & 87 & 99 \\
\hline 42 & M & 64 & $\mathrm{R}$ & 0.2 & 6.2 & - & 3.4 & 160 & 21 & - & 24 \\
\hline 43 & $\mathrm{~F}$ & 75 & $\mathrm{X}$ & 0.3 & 7 & - & 3.3 & 0 & 0 & - & 1 \\
\hline 45 & M & 84 & $\mathrm{X}$ & 1.2 & 6.1 & 98 & 7.2 & 0 & 0 & 0 & 2 \\
\hline 46 & $\mathrm{~F}$ & 69 & $\mathrm{X}$ & 1.7 & 6.7 & 92 & 5.8 & 0 & 0 & 1 & 5 \\
\hline 47 & $\mathrm{~F}$ & 78 & $\mathrm{H}$ & 0.7 & 7.7 & 121 & 2.9 & 66 & 29 & 116 & 192 \\
\hline 48 & $\mathrm{~F}$ & 73 & $\mathrm{X}$ & 0.5 & 7.1 & 84 & 7.1 & 131 & 120 & 104 & 91 \\
\hline 49 & $\mathrm{~F}$ & 84 & $\mathrm{X}$ & 4 & 10 & - & 7 & 0 & 0 & - & 0 \\
\hline 50 & M & 69 & V & 0.1 & 5.2 & 76 & 4.2 & 221 & 211 & 250 & 273 \\
\hline 52 & M & 81 & V & 0.9 & 7.9 & 122 & 7 & 19 & 17 & 43 & 10 \\
\hline 54 & $\mathrm{~F}$ & 22 & $\mathrm{R}$ & 1.7 & 8.7 & 111 & 0.8 & 40 & 6 & 24 & 22 \\
\hline 55 & $\mathrm{~F}$ & 71 & $\mathrm{X}$ & 1.9 & 5.8 & - & 5.8 & 43 & 89 & - & 10 \\
\hline 56 & $\mathrm{~F}$ & 83 & $X$ & 4 & - & - & 8.3 & 0 & - & - & 1 \\
\hline 57 & $\mathrm{~F}$ & 73 & $\mathrm{H}$ & 1.8 & 9 & 132 & 9.8 & 1 & 6 & 63 & 52 \\
\hline 58 & M & 44 & $\mathrm{R}$ & 0.8 & 5.9 & 95 & 1 & 17 & 13 & 51 & 22 \\
\hline 59 & $\mathrm{~F}$ & 82 & $\mathrm{X}$ & 1.1 & 9.1 & 92 & 5.2 & 5 & 9 & 10 & 3 \\
\hline \multirow[t]{2}{*}{60} & & 66 & $\mathrm{X}$ & 1.3 & 6.1 & 84 & 5 & 25 & 29 & 40 & 24 \\
\hline & \multicolumn{3}{|c|}{ Median } & 1.1 & 6.8 & 95 & & 18 & 6 & 19 & \\
\hline
\end{tabular}

$\mathrm{H}=$ hyperaemic $\mathrm{R}=$ relative $\mathrm{V}=$ detected on volume measurements only; $\mathrm{X}=$ no evidence for reperfusion.

known and the deficit maximal at onset. A source (either cardiac or artery to artery) of embolus had to be present without preeminent evidence of a thrombotic cause. Gradual onset was considered incompatible with an embolic aetiology. When the mode of onset was uncertain (insufficient information or the patient woke with the deficit) the cause was diagnosed as embolic if there was a substantial cause of embolism without substantial evidence of a thrombotic cause. Lesions of deep perforating arteries without a source of embolism were diagnosed as thrombotic (and were often lacunar). Cases with conflicting aetiological evidence were left unclassified. Whereas occlusion of branches of the major cerebral arteries is thought to be most commonly embolic ${ }^{24}$ this factor was subordinated to the speed of onset such that a branch occlusion arising slowly was classified as thrombotic. Otherwise, branch occlusion was considered to favour an embolic aetiology.
Patients with and without reperfusion were compared for perfusion defect, aetiology, oedema, and haemorrhagic infarction.

In some cases in which hyperaemia was seen, the second scan was repeated about six hours later without further injection of ${ }^{99} \mathrm{Tc}^{\mathrm{m}}$ HMPAO, looking for evidence of redistribution of ${ }^{99} \mathrm{Tc}^{\mathrm{m}}$ HMPAO. The changes within these volumes were heterogeneous. These small focal changes were analysed using individual regions of interest, which were not summed together. This analysis was confined to grey matter. Typically one or two slices from each pair of scans were chosen for more detailed study, the region of interest being placed manually with the closest possible match for anatomical site and the percentage change in counts per region of interest between the early and late scans calculated. We adjusted for decay by using the ratio of the total counts in the slices studied. 
Table 2 Abnormal/normal ${ }^{99} \mathrm{TC}^{m}$ HMPAO uptake ratios for those cases in which reperfusion was identified

\begin{tabular}{|c|c|c|c|c|c|c|c|c|c|}
\hline \multirow[b]{2}{*}{ Case No } & \multirow[b]{2}{*}{ Age/sex } & \multirow[b]{2}{*}{ Type } & \multicolumn{2}{|c|}{ First study } & \multicolumn{2}{|c|}{ Second study } & \multirow{2}{*}{$\begin{array}{l}\text { Third } \\
\text { study }\end{array}$} & \multicolumn{2}{|c|}{ Extra study } \\
\hline & & & Initial & Wash & Initial & Wash & & Initial & Wash \\
\hline 2 & $77 / \mathrm{F}$ & $\mathrm{H}$ & 1.289 & - & 1.203 & - & 0.975 & - & - \\
\hline 5 & $66 / F$ & $\mathrm{H}$ & 0.738 & - & 1.201 & 1.136 & 0.572 & - & - \\
\hline 7 & $76 / \mathrm{F}$ & $\mathrm{R}$ & 0.926 & - & 1.000 & - & 0.932 & - & - \\
\hline 11 & $72 / \mathrm{M}$ & $\mathrm{H}$ & 0.597 & - & 1.067 & 1.122 & 0.686 & - & - \\
\hline 16 & $81 / \mathrm{F}$ & $\mathrm{H}$ & 1.064 & - & 1.082 & - & - & - & - \\
\hline 20 & $80 / \mathrm{F}$ & $\mathrm{R}$ & 0.925 & - & 1.001 & - & 0.859 & - & - \\
\hline 27 & $59 / \mathrm{F}$ & $\mathrm{H}$ & 1.236 & 1.306 & 1.068 & - & 0.932 & 1.122 & 1.101 \\
\hline 28 & $77 / \mathrm{F}$ & $\mathrm{R}$ & 0.822 & - & 1.032 & - & 0.780 & - & - \\
\hline 38 & $43 / \mathrm{M}$ & $\mathrm{H}$ & 0.428 & - & 1.072 & - & - & - & - \\
\hline 42 & $64 / \mathrm{M}$ & $\mathrm{R}$ & 0.732 & - & 1.030 & - & - & - & - \\
\hline 47 & $78 / \mathrm{F}$ & $\mathrm{H}$ & 0.976 & - & 1.224 & - & 0.643 & - & - \\
\hline 54 & $22 / \mathrm{F}$ & $\mathrm{R}$ & 0.865 & - & 1.070 & - & 0.659 & - & - \\
\hline 57 & $73 / \mathrm{F}$ & $\mathrm{H}$ & 1.120 & 1.146 & 0.951 & - & 0.764 & - & - \\
\hline 58 & $44 / M$ & $\mathrm{R}$ & 0.849 & - & 0.784 & - & 0.825 & - & - \\
\hline
\end{tabular}

$\mathrm{H}=$ hyperaemic; $\mathrm{R}=$ relative as defined in the text.

\section{Results}

In the 50 consecutive patients with ischaemic stroke who entered the study 124 SPECT scans were taken. Table 1 shows details of scanning times and perfusion defect measurements. Fourteen cases (28\%) exhibited reperfusion, which was hyperaemic in eight $(57 \%)$. In four of the eight, reperfusion was seen on the first SPECT but involved only part of the volume of the infarct in three of the four. In six of 14 patients (43\%), reperfusion was relative and seen on the second SPECT. Reperfusion was never seen on the three month scan. Table 2 shows details of HMPAO uptake in the reperfused regions. Reperfusion inferred from an apparent fall in the perfusion defect in the second SPECT compared with both the first and third SPECT in seven further cases of the 26 cases in which this could be sought (having completed all three scans with no visible reperfusion and with the infarct visible on at least the first and third scans). As these cases were self selecting for survival to three months, primary analysis counted these cases as not reperfused;

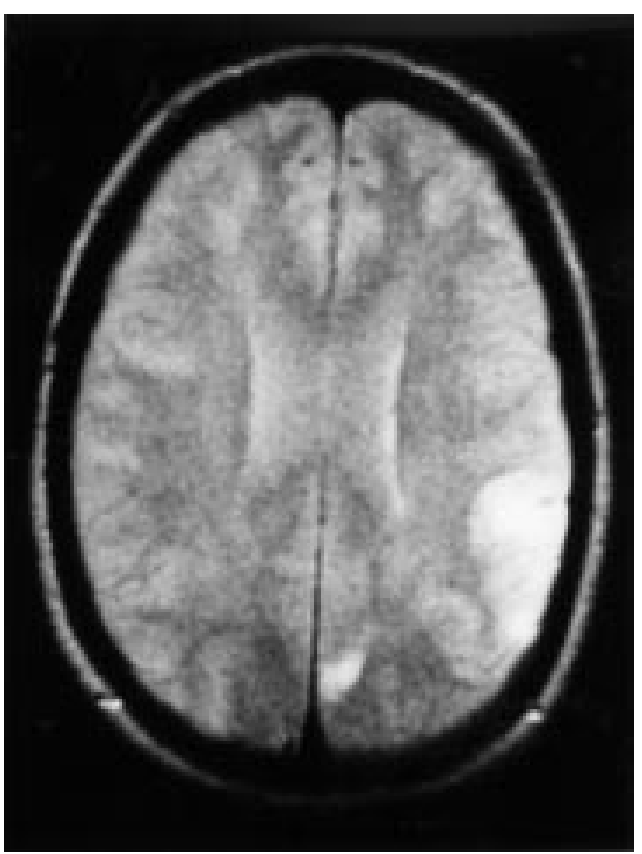

Figure 3 MRI at six weeks showing increased signal limited to the posterior portion of the extensive area of cortical hyperaemia seen in the first SPECT (fig 1). secondary analysis included them as reperfused. This did not materially alter the findings.

Perfusion defect volumes were not normally distributed (table 1). The SPECT perfusion defect decreased between the first and second scans without reaching significance. There was an increase in perfusion defect between the second and third examinations (medians 6 and $19 \mathrm{~cm}^{3}$ respectively, $\mathrm{p}<0.001$, Wilcoxon signed ranks). We calculated early reperfusion volumes (first-second scan perfusion deficit 15.3 (SD 40.4) $\mathrm{cm}^{3}$, late reperfusion (second-third month scan -22.0 (SD 31.5) $\mathrm{cm}^{3}$ ), and total reperfusion (first-third scan-10.1 (SD 19.5) $\mathrm{cm}^{3}$ ). Thus the mean decrease in the perfusion defect of $15 \mathrm{~cm}^{3}$ in the first week was followed by an increase of $22 \mathrm{~cm}^{3}$ by three months-that is, in the 33 cases for whom there are complete data, nutritional reperfusion ${ }^{1}$ amounted to 10 $\mathrm{cm}^{3}$ and non-nutritional to $12 \mathrm{~cm}^{3}$.

Analyses for CT infarct volume and for clinical outcome using the Canadian neurological scale score at each clinical examination and the Barthel index at the final examination showed no differences between those with and without reperfusion. Similarly,

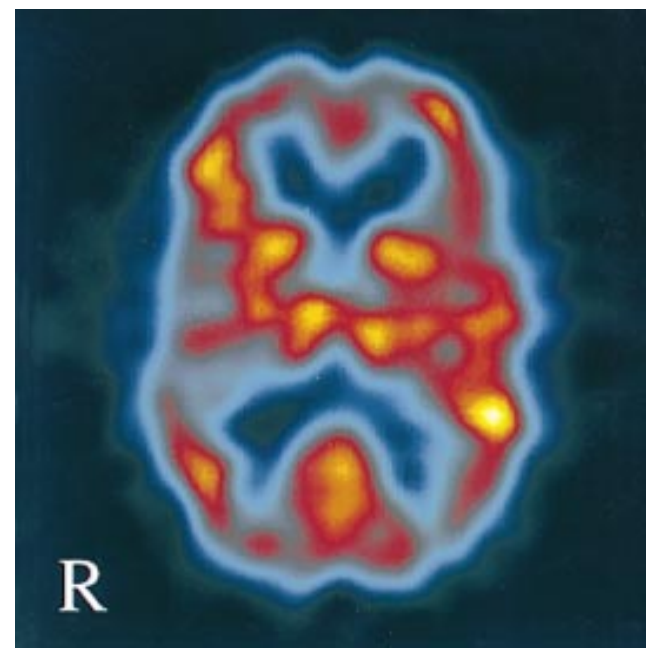

Figure 4 A second middle cerebral artery embolism 64 days after the first event in the same case as figures 1 and 3 , scanned 48 hours after onset, produced similar, but less intense, absolute hyperaemia as the initial event. SPECT had returned to normal before this. 


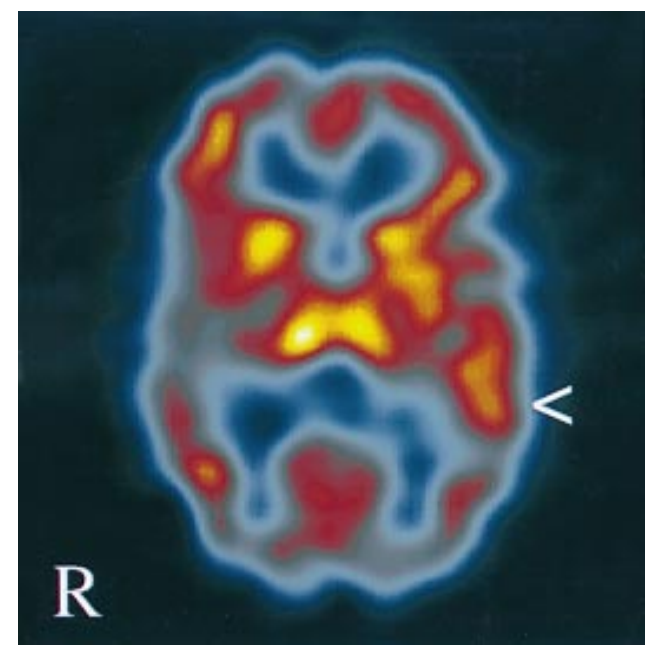

Figure 5 Repeat SPECT six hours after injection of ${ }^{99} \mathrm{Tc}^{m}-\mathrm{HMPAO}$ (fig 4) shows partial washout of ${ }^{99} \mathrm{Tc}^{m}$-HMPAO, most striking at the centre of the lesion (arrowhead).

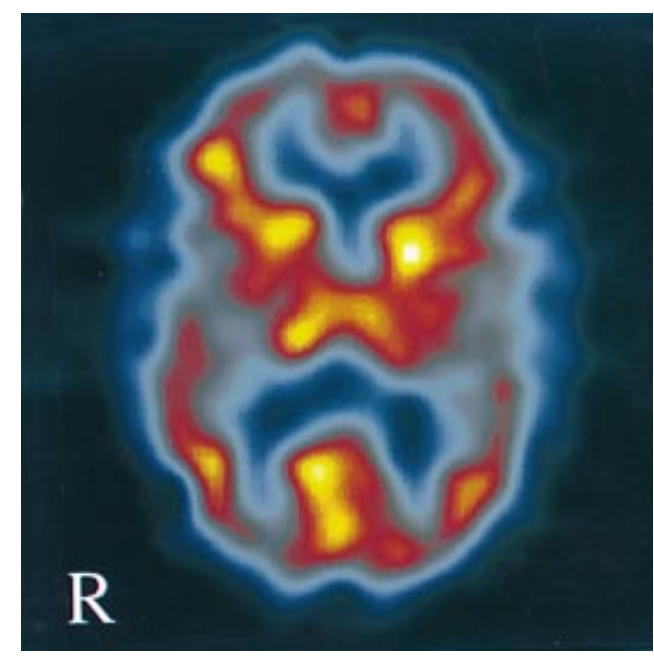

Figure 6 Final SPECT in the case shown in figs 4 and 5, performed 25 days later, showing a modest perfusion deficit in the centre of the region previously showing the most intense reperfusion.

measures of nutritional and non-nutritional reperfusion had no assocation with outcome.

Reperfusion was without effect on the incidence of oedema, which was identified in $14(29 \%)$ of the 49 cases with CT ( $p=0.684 ; \chi^{2}$ with Yates' correction). As oedema was not seen in small lesions for reasons that may be artefactual, the data were reanalysed for lesions above $20 \mathrm{~cm}^{3}$ but this made no difference ( $p=0.325 ; \chi^{2}$ with Yates' correction).

Haemorrhagic transformation was seen in six cases $(12 \%)$ and reperfusion was present in four of these ( $p=0.078, \chi^{2}=3.1$ with Yates' correction), suggesting an association between these, but with small numbers.

We classified the aetiology in 46 cases (92\%). Of these, 13 of 23 embolic lesions and three of 23 thrombotic cases were reperfused $(\mathrm{p}=0.049$, $\left.\chi^{2}=6.04\right)$. The statistical significance increased $\left(\mathrm{p}=0.0173, \chi^{2}=8.1\right)$ when reperfusion inferred from volume measurements was included. Embolic lesions were neither more often haemorrhagic nor oedematous than thrombotic lesions.

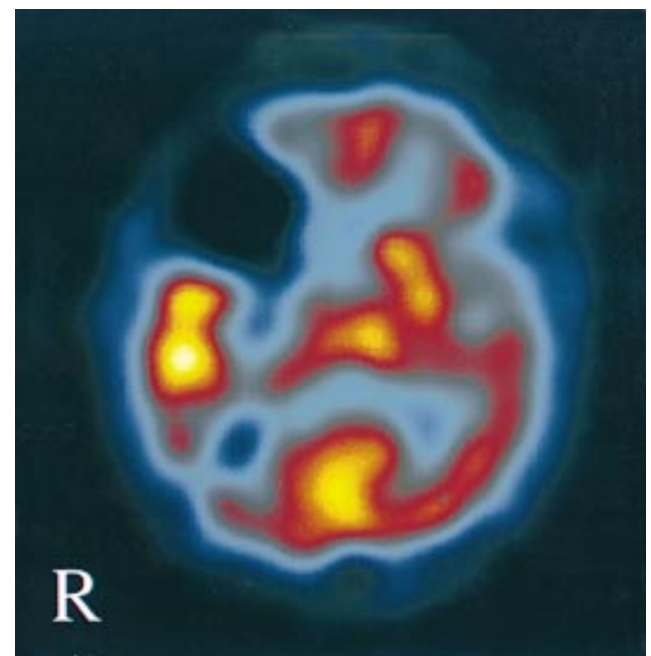

Figure 7 First SPECT in case 2, at 0.8 days, showing a perfusion deficit in the anterior part of the middle cerebral artery territory, with a zone of hyperaemia posterior to this and a zone of decreased perfusion in the parieto-occipital region. The basal ganglia and adjacent regions are not reperfused.

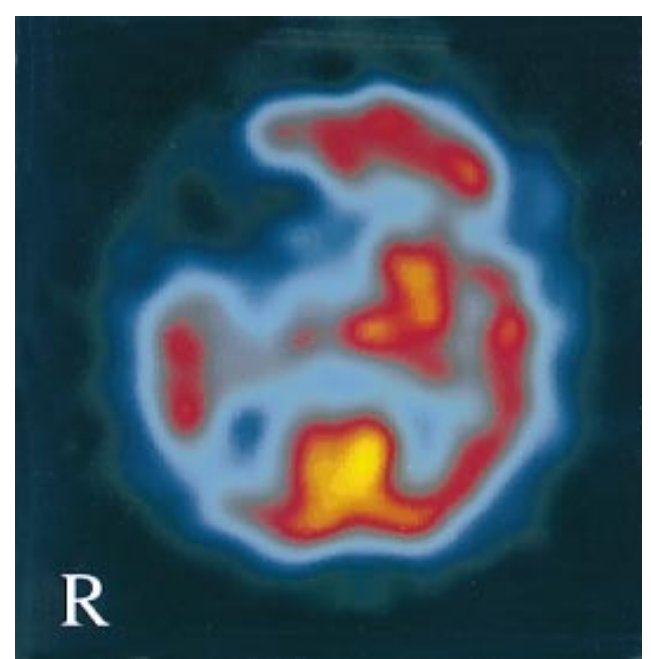

Figure 8 Final SPECT in case 2, at 106 days, showing that the central part of the region is preserved,

corresponding to the hyperaemic region in fig 7 , but that it is surrounded by infarcted tissue and is presumed to be functionally disconnected.

Reperfusion was identifiable on the first SPECT in four cases. In only one case did early reperfusion preserve neuronal tissue so that it remained functional and connected, so influencing the clinical course. In one other case there was early hyperaemic reperfusion limited to the superficial cortical part of an embolic lesion which survived according to ${ }^{99} \mathrm{Tc}^{\mathrm{m}}$ HMPAO uptake at three months. However, it had no clinically detectable function, presumably because it was disconnected from the remainder of the brain as the surrounding tissues were infarcted.

\section{CASE REPORT}

A 59 year old female right handed librarian with a five year history of well treated hypertension and no other stroke risk factors reported two episodes of one minute duration of expressive aphasia and one episode of one minute of right sided tingling in the six months 


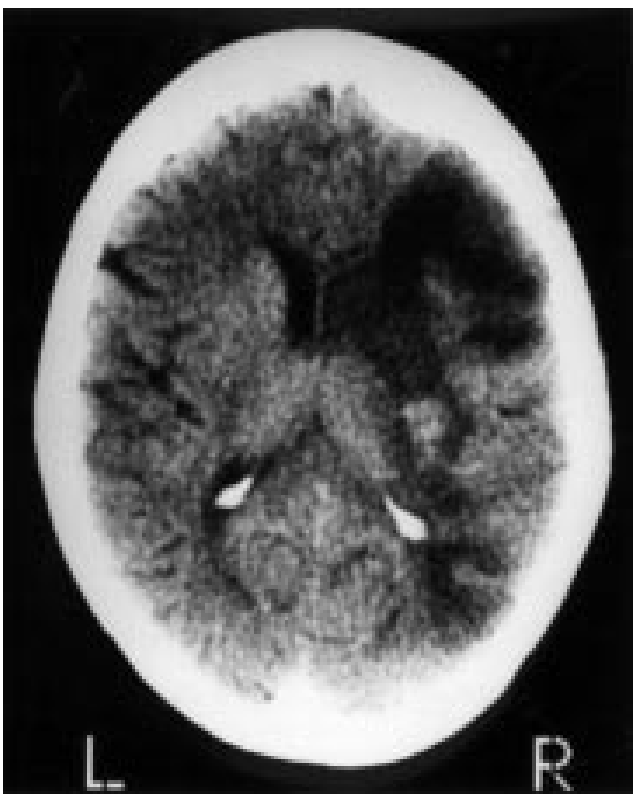

Figure 9 CT in case 2, at one day showing low density changes consistent with infarction in the anterior, posterior, and medial parts of the middle cerebral artery territory, but with a large spared central portion.

before presentation. On the day of presentation she woke unable to speak but with full comprehension. She had no weakness or sensory disturbance and walked normally to her telephone to dial her workplace, but on being answered could not speak. Her speech began to return three hours after waking. Unenhanced CT at eight hours was normal.

Twenty four hours after onset her speech on bedside testing was normal in content and without errors but slow. There was minimal right upper motor neuron facial weakness and a mild right sided cortical sensory deficit but no other signs. SPECT showed an average $24 \%$ increase in ${ }^{99} \mathrm{Tc}^{\mathrm{m}} \mathrm{HMPAO}$ retention in the cortical distribution of the left middle cerebral artery compared with the right (fig 1). Full haematological investigation, chest radiography, ECG, and carotid duplex Doppler were normal. Echocardiography disclosed an enlarged left atrium. At five days, CT showed slight cortical low density on one slice, SPECT was normal and no clinical signs remained. Neuropsychological assessment showed only impaired verbal fluency. Brain MRI at six weeks showed increased signal limited to the posterior part of the extensive cortical distribution seen in the first SPECT and similarly spared the white matter (fig 3). Despite aspirin, she had a further similar event two months after the first but with less complete recovery on neuropsychological evaluation. She was anticoagulated. SPECT at 48 hours after the second event showed increases averaging $12 \%$ (range $8 \%$ to $54 \%$ ) in the left middle cerebral artery cortical territory (fig 4). A further scan six hours later (fig 5) showed partial washout of $10 \%$ overall (not significant), but it was limited to the central zone, where the volumes had the highest uptake. Here the excess retention fell from $54 \%$ to $26 \%$. A final SPECT one month later showed persisting perfusion deficits con- sistent with patchy infarction at the centre of the affected volume (fig 6).

Repeat scans six hours after injection, looking for redistribution of ${ }^{99} \mathrm{Tc}^{\mathrm{m}}$ HMPAO after hyperaemic reperfusion, were carried out on five occasions (table 2). The case described above was the only one in which substantial redistribution was seen. After the first event there was an overall increase in retention, from $124 \%$ to $131 \%$ of the opposite side but in some individual regions of interest at the centre of the lesion there was evidence of washout reaching a maximum of $-27 \%$. More peripherally there was an increase in uptake. At the second event there was slight overall washout, from $112 \%$ to $110 \%$ of the opposite side but focally this reached a maximum of $-35 \%$. In the other cases studied there were no significant global or focal changes in retention, focal changes ranging between between $-13 \%$ and $+6 \%$. These figures lie within the $95 \%$ confidence intervals for small regions of interest. $^{23}$ In one case there was a nonreperfused region and here there was a significant increase in retention, from +31 to $+42 \%$ in individual regions of interest.

\section{Discussion}

In this study $28 \%$ of cases exhibited reperfusion directly visible on SPECT and a further $14 \%$ had evidence of reperfusion deduced from perfusion deficit volume measurements. This proportion is in keeping with other studies done at a similar time after stroke, ${ }^{3} 91025-28$ suggesting similar criteria for defining reperfusion. Nevertheless, the meaning of "reperfusion" seen with ${ }^{99} \mathrm{Tc}^{\mathrm{m}}$ HMPAO is uncertain. Its uptake is dependent not only on local cerebral blood flow but also intracellular glutathione, ${ }^{29}{ }^{30}$ although more recent evidence suggests a primary role for the extracellular redox state. ${ }^{31}$ Furthermore, three case reports ${ }^{32}$ suggest that ${ }^{99} \mathrm{Tc}^{\mathrm{m}} \mathrm{HMPAO}$ may overestimate cerebral blood flow. However, there has been no conclusive confirmation of this report. Some support comes from four cases of acute infarction imaged with both PET and ${ }^{99} \mathrm{Tc}^{\mathrm{m}}$ HMPAO SPECT. In two cases, ${ }^{99} \mathrm{Tc}^{\mathrm{m}}$ HMPAO retention exceeded that expected from the PET study, although in both these cases the ${ }^{99} \mathrm{Tc}^{\mathrm{m}}$ HMPAO study was done two days after the PET. In the other two cases, where the ${ }^{99} \mathrm{Tc}^{\mathrm{m}}$ HMPAO and PET studies were separated by only one day, the findings were concordant. ${ }^{33}$ The authors, therefore, cannot conclusively confirm spurious hyperfixation. However, uncertainty over this point means that our comments may apply only to phenomena found with ${ }^{99} \mathrm{Tc}^{\mathrm{m}}$ HMPAO. Similarly, we have avoided the term "luxury perfusion" because its meaning varies according to the technique used to identify it. Originally it was a simple increase in cerebral blood flow above that normally expected at that site. ${ }^{2}$ With the arrival of metabolic studies and PET, the term was equated with a low oxygen extraction ratio irrespective of local cerebral blood flow. The importance of the distinction was shown by Baron $e a^{28}$; a low oxygen extraction ratio was 
found in $82 \%$ of infarcts less than 31 days old but, in these, cerebral blood flow was decreased in $52 \%$, normal in $34 \%$, and increased in only $14 \%$.

The mean time of the 14 SPECT scans showing reperfusion was 5.8 days from onset and 10 of these had earlier scans that did not show reperfusion, suggesting that spontaneous reperfusion usually occurs after the first day. This is supported by most studies that have identified spontaneous reperfusion, which usually report its occurrence within two weeks of the ictus. ${ }^{3-68-103435}$ One study reported that one third of cases had reperfused within 18 hours of onset. $^{36}$ However, two thirds were embolic. This unusually high proportion may explain the finding.

In the two cases in which reperfusion was early enough to preserve tissue, both showed reperfusion in the first scan. In one it was patchy, probably reflecting distal migration of embolic fragments ${ }^{5}$ and the surviving tissue was disconnected from the rest of the brain, rendering it functionally useless (figs $7-9^{7-9}$ ). Functionally beneficial spontaneous reperfusion is therefore rare, occurring in one in 50 cases and these findings are consistent with other work. ${ }^{57273738}$ Volumetric analysis suggests that the mean benefit of spontaneous reperfusion is the preservation of $10 \mathrm{~cm}^{3}$ of tissue, corresponding to the nutritional reperfusion reported by Infeld et al. ${ }^{1}$

Perhaps more important in view of the increasing interest in thrombolytic treatment is the demonstration in one case that early reperfusion may enable full recovery, even after a total middle cerebral artery event. In the case report above, symptoms were present for three hours, and probably longer, as they were present on waking. However, as the clinical deficit was limited to dysphasia despite changes throughout the middle cerebral artery territory, it seems likely that reperfusion had already occurred by the time of awakening and this is supported by the association of early reperfusion with embolic events. ${ }^{36}$ The extensive cortical changes on MRI, with only trivial dysphasia, suggest that the cortex underwent a change detectable on MRI that did not involve extensive neuronal loss, perhaps a form of incomplete infarction. ${ }^{39}$ Similar cases have rarely been reported. In a study of reperfusion after cerebral infarction using radioactive xenon, three cases were identified without defects on CT despite pronounced hyperaemia on xenon cerebral blood flow studies. ${ }^{5}$ One of these involved dysphasia lasting two days, akin to the case here.

The increase in CT infarct volume between the second day and a week probably reflects increasing oedema rather than infarct volume as the SPECT perfusion defect, detecting reperfusion, usually remained constant or decreased at one week, a common finding. ${ }^{26} 27384041$

Oedema, seen in $29 \%$ of cases, was not significantly associated with spontaneous reperfusion. This suggests that the ingress of oedema fluid is not driven by arterial perfusion, and we hypothesise that it arises by retrograde venous flow, or from the adjacent cerebral parenchyma.

Although the association between reperfusion and haemorrhagic transformation did not reach significance, four of six haemorrhagic infarcts were associated with reperfusion. We suspect that the failure to detect an association was a false negative due to small numbers, as an association has been suggested by others ${ }^{42}$ and is biologically plausible.

Costa and $\mathrm{Ell}^{19}$ reported that $18.5 \%$ washout of ${ }^{99} \mathrm{Tc}^{\mathrm{m}} \mathrm{HMPAO}$ from an infarct might reflect a good prognosis. Our single case in which this was seen supports this suggestion, but the full series of 50 cases show that it is rare. It is also inconstant, not always being seen in reperfused tissue that survived and patchy when it was, being restricted to the lesion's centre. More peripheral areas that were reperfused and survived did not show wash out; they exhibited either no change or a slight increase. The process underlying wash out has not been fully explained. Usually after cerebral infarction, no change in ${ }^{99} \mathrm{Tc}^{\mathrm{m}}$ content, or an increase due to the influx of free ${ }^{99} \mathrm{Tc}^{\mathrm{m}}$ pertechnetate, is expected. A fall must represent a different process. Washout from an increased cerebral blood plasma volume has been suggested as ${ }^{99} \mathrm{Tc}^{\mathrm{m}} \mathrm{HMPAO}$ is cleared from the plasma by the liver. ${ }^{43}$ However, the plasma volume available and its proportionate uptake could not account for washout of more than $6 \% .^{23} 44$ Leakage of converted ${ }^{99} \mathrm{Tc}^{\mathrm{m}} \mathrm{HMPAO}$ may offer a better explanation. ${ }^{26}$

We conclude that spontaneous reperfusion occurs in $42 \%$ of cases of cerebral infarction, usually between one day and one week after stroke. When all the cases are analysed volumetrically there is evidence for salvage of a mean of $10 \mathrm{~cm}^{3}$ of tissue by nutritional reperfusion, although most reperfusion is nonnutritional. Extensive preservation of tissue is rare (4\% of cases) and requires very early reperfusion. Spontaneous reperfusion is not associated with cerebral oedema but may be with haemorrhagic transformation. The natural history of reperfusion mirrors the recent trials of thrombolytic therapy in which gainful reperfusion can only be shown after treatment within three hours and is bought at the cost of more frequent haemorrhagic transformation.

JVB was supported by the Stroke Association.

1 Infeld B, Davis SM, Donnan GA, et al. Streptokinase increases luxury perfusion after stroke. Stroke increases luxur

2 Lassen NA. The luxury perfusion syndrome and its possible relation to acute metabolic acidosis localised within the brain. Lancet 1966;ii:1113-5.

3 Olsen TS, Larsen B, Skriver EB, Herning M, Enevoldsen E, Lassen NA. Focal cerebral hyperaemia in acute stroke. Incidence, pathophysiology and clinical significance. Stroke 1981;12:598-607.

4 Uemura K, Goto K, Ishii K, Ito Z, Hen R, Kawakami H. Sequential changes of regional cerebral blood circulation in cerebral infarction. Neuroradiology 1978;16:228-32.

5 Olsen TS, Lassen NA. A dynamic concept of middle cerebral artery occlusion and cerebral infarction in the acute state based on interpreting severe hyperemia as a sign of embolic migration. Stroke 1984;15:458-68.

6 Ackerman RH, Lev MH, Mackay BC, et al. PET studies in acute stroke. Findings and relevance to therapy. $f$ Cereb Blood Flow Metab 1989;9(suppl 1):S359

7 Smith FW, Donald RT, Morris AJ, Sharp PF, Gemmell HG. The study of regional cerebral blood flow in stroke patients using technetium 99m HMPAO. Br f Radiol 1988;61:358 61 . 
8 Hakim AM, Pokrupa RP, Villanueva J, et al. The effect of spontaneous reperfusion on metabolic function in early

9 Baird AE, Donnan GA, Austin M, Newton MR, McKay WJ. Preliminary experience with $99 \mathrm{mTc}$-HMPAO SPECT in cerebral ischaemia. Clin Exp Neurol 1991;28:43-9.

10 Alexandrov AV, Ehrlich LE, Bladin CF, Black SE. Clinica significance of increased uptake of HMPAO on brain SPECT scans in acute stroke. $\mathcal{f}$ Neuroimaging 1996;6:1505.

11 Inugami A, Kanno I, Uemura K, et al. Linearization correction of $99 \mathrm{mTc}$-labeled hexamethyl-propylene amine oxime (HM-PAO) image in terms of regional cerebral blood flow distribution: comparison to $\mathrm{C}_{15} \mathrm{O}_{2}$ inhalation steady-state method measured by positron emission tomography. $\mathcal{F}$ Cereb Blood Flow Metab 1988;8(suppl)S52-60.

12 Nakano S, Kinoshita K, Jinnouchi S, Hoshi H, Watanabe K. Comparative study of regional cerebral blood flow images by SPECT using xenon-133, iodine-123 IMP, and technetium-99m HM-PAO. F Nucl Med 1989;30:157-64.

13 Yonekura Y, Nishizawa S, Mukai T, et al. SPECT with $99 \mathrm{mTc}$-d,1-hexamethyl-propylene amine oxime (HMPAO) compared with regional cerebral blood flow measured by PET: effects of linearization. $\mathcal{F}$ Cereb Blood Flow Metab 1988;8(suppl):S82-9.

14 Costa DC, Jones BE, Steiner TJ, et al. Experimental studies of Tc $99 \mathrm{~m}$ HMPAO with an rCBF model [abstract]. Nucl Med Commun 1986;7:282-3.

15 Andersen AR, Friberg H, Lassen NA, Kristensen K, Neirinckx RD. Serial studies of cerebral blood flow usin 99Tcm-HMPAO: a comparison with ${ }^{133} \mathrm{Xe}$. Nucl $\mathrm{Med}$ Commun 1987;8:549-57.

16 Bowler JV, Wade JPH, Jones BE, Nijran K, Steiner TJ. Single-photon emission computed tomography using hexamethlypropyleneamine oxime in the prognosis of acute cerebral infarction. Stroke 1996;27:82-6.

17 Davis SM, Chua MG, Lichtenstein M, Rossiter SC, Binns $\mathrm{D}$, Hopper JL. Cerebral hypoperfusion in stroke prognosis D, Hopper JL. Cerebral hypoperfusion in st

18 Alexandrov AV, Black SE, Ehrlich LE, et al. Simple visual analysis of brain perfusion on HMPAO SPECT predicts analysis of brain perfusion on HMPAO SPECT predicts

19 Costa DC, Ell PJ. 99m Tc-HMPAO washout in prognosis of stroke. Lancet 1989;1:213-4.

20 Bowler JV, Wade JPH, Jones BE, et al. The contribution of diaschisis to the clinical deficit in human cerebral infarction. Stroke 1995;26:1000-6.

21 Cote R, Hachinski VC, Shurvell BL, Norris JW, Wolfson C. The Canadian neurological scale: a preliminary study in acute stroke. Stroke 1986;17:731-7.

22 Mahoney FI, Barthel DW. Functional evaluation; the Barthel index. Maryland State Medical fournal 1965;14:615 .

23 Bowler JV. Cerebral infarction and ${ }^{99} \mathrm{Tc}^{\mathrm{m}}$ HMPAO SPECT [MD thesis]. London: University of London, 1993.

24 Bamford J, Sandercock P, Dennis M, Burn J, Warlow C. Classification and natural history of clinically identifiable subtypes of cerebral infarction. Lancet 1991;337:1521-6.

25 Ackerman RH, Alpert NM, Correia JA, et al. Importance of monitoring metabolic function in assessing the severity of a
stroke insult (CBF: an epiphenomenon?). $\mathcal{F}$ Cereb Blood Flow Metab 1981;1(suppl 1):S502-3.

26 Limburg M, van Royen EA, Hijdra A, de Bruine F ${ }^{99 \mathrm{~m}} \mathrm{Tc}-\mathrm{HMPAO}$ washout in prognosis of stroke. Lance 1989;i:839-840.
27 Limburg $M$, van Royen EA, Hijdra A, Verbeeten B. rCBF-SPECT in brain infarction: when does it predict rCBF-SPECT in brain infarction: whe
outcome? F Nucl Med 1991;32:382-7.

28 Baron JC, Bousser MG, Comar D, Soussaline F, Castaigne P. Non-invasive tomographic study of cerebral blood flow and oxygen metabolism in vivo. Eur Neurol 1981;20:27384 .

29 Suess E, Huck S. 99m Tc HMPAO accumulation in cultured neurons. F Cereb Blood Flow Metab 1989;9(suppl 1):S735.

30 Neirinckx RD, Burke JF, Harrison RC, Forster AM, Andersen AR, Lassen NA. The retention mechanism of technetium 99m HMPAO: intracellular reaction with glutathione. f Cereb Blood Flow Metab 1988;8(suppl):S4glut 12 .

31 Jacquier-Sarlin MR. Oxido-reductive state: the major determinant for cellular retention of technetium-99m-HMPAO. f Nucl Med 1996;37:1413-6.

32 Sperling B, Lassen NA. Hyperfixation of HMPAO in subacute ischemic stroke leading to spuriously high estimates of CBF by SPECT. Stroke 1993;24:193-4.

33 Shishido F, Uemura K, Inugami A, et al. Discrepant $99 \mathrm{mTc}-\mathrm{ECD}$ images of CBF in patients with subacute cer99mTc-ECD images of $\mathrm{CBF}$ in patients with subacute cer99mTc-HMPAO imaging. Ann Nucl Med 1995;9:161-6.

34 Moretti JL, Defer G, Cinotti L, et al. Luxury perfusion with $99 \mathrm{mTc}-\mathrm{HMPAO}$ and ${ }^{123}$ I-IMP SPECT imaging during the subacute phase of stroke. Eur f Nucl Med 1990;16:17-22.

35 Feldmann $M$, Voth E, Dressler D, Henze T, Felgenhauer K. ${ }^{99 \mathrm{~m}} \mathrm{Tc}$-hexamethypropylene amine oxime SPECT and X-ray CT in acute cerebral ischaemia. $\mathcal{F}$ Neurol 1990;237: $475-9$.

36 Marchal G, Serrati C, Rioux P, et al. PET imaging of cerebral perfusion and oxygen consumption in acute ischaemic stroke: relation to outcome. Lancet 1993;341: 925-7.

37 Demeurisse G, Verhas M, Capon A, Paternot J. Lack of evolution of the cerebral blood flow during clinical recovery of a stroke. Stroke 1983;14:77-81.

38 Heiss WD, Huber M, Fink GR, et al. Progressive derangement of periinfarct viable tissue in ischemic stroke. 7 Cereb Blood Flow Metab 1992;12:193-203.

39 Garcia JH, Lassen NA, Weiller C, Sperling B, Nakagawara J. Ischemic stroke and incomplete infarction. Stroke 1996;27: $761-5$.

40 Brott T, Marler JR, Olinger CP, et al. Measurements of acute cerebral infarction: lesion size by computed tomography. Stroke 1989;20:871-5.

41 Rango M, Candelise L, Perani D, et al. Cortical pathophysiology and clinical neurologic abnormalities in acute cerebral ischemia. A serial study with single photon emission computed tomography. Arch Neurol 1989;46: 1318-22.

42 Yamaguchi T, Minematsu K, Choki J, Ikeda M. Clinical and neuroradiological analysis of thrombotic and embolic cerebral infarction. Fpn Circ f 1984;48:50-8.

43 Hayashida K, Nishimura T, Imakita S, Uehara T. Filling out phenomenon with technetium-99m HM-PAO brain phenomenon with technetium-99m HM-PAO brain 1989;30:591-8.

44 Podreka I, Suess E, Goldenberg G, et al. Initial experience with technetium-99m HM-PAO brain SPECT. $\mathcal{F}$ Nucl Med 1987;28:1657-66. 